\title{
Outcomes beyond the Third Month of Anticoagulation in Patients Aged $>75$ Years with a First Episode of Unprovoked Venous Thromboembolism
}

\author{
Amaia Iñurrieta ${ }^{1}$ José María Pedrajas ${ }^{1}$ Manuel Jesús Núñez ${ }^{2} \quad$ Luciano López-Jiménez ${ }^{3}$ \\ Alba Velo-García ${ }^{2}$ Juan Carlos García ${ }^{2}$ Ramón Lecumberri ${ }^{4}$ David Jiménez ${ }^{5}$ Isaac Pons ${ }^{6}$ \\ Manuel Monreal ${ }^{7}$ and the RIETE Investigators*
}

\footnotetext{
1 Department of Internal Medicine, Hospital Clínico San Carlos, Madrid, Spain

2 Department of Internal Medicine, Complejo Hospitalario de

Pontevedra, Pontevedra, Spain

${ }^{3}$ Department of Internal Medicine, Hospital Universitario Reina Sofía, Córdoba, Spain

${ }^{4}$ Department of Haematology, Clínica Universidad de Navarra,

Pamplona, Spain

${ }^{5}$ Department of Pneumonology, Hospital Ramón y Cajal, Madrid, Spain

${ }^{6}$ Department of Internal Medicine, Hospital de Igualada, Barcelona, Spain

${ }^{7}$ Department of Internal Medicine, Universidad Católica de Murcia,

Hospital de Badalona Germans Trias i Pujol, Murcia, Spain
}

Address for correspondence Amaia Iñurrieta, MD, Servicio de Medicina Interna, Hospital Clínico San Carlos, 28040 Madrid, Spain (e-mail: amaiainu@hotmail.com).

TH Open 2018;2:e428-e436.

\begin{abstract}
Background The ideal duration of anticoagulant therapy in elderly patients with unprovoked venous thromboembolism (VTE) has not been consistently evaluated. Methods We used the RIETE (Registro Informatizado Enfermedad TromboEmbólica) registry to compare the rate and severity of pulmonary embolism (PE) recurrences versus major bleeding beyond the third month of anticoagulation in patients $>75$ years with a first episode of unprovoked VTE.

Results As of September 2017, 7,830 patients were recruited: 5,058 (65\%) presented with $\mathrm{PE}$ and 2,772 with proximal deep vein thrombosis (DVT). During anticoagulant therapy beyond the third month (median, 113 days), 44 patients developed PE recurrences, 36 developed DVT recurrences, 101 had major bleeding, and 241 died (3 died of recurrent PE and 19 of bleeding). The rate of major bleeding was twofold higher than the rate of PE recurrences (2.05 [95\% confidence interval, Cl: $1.68-2.48$ ] vs. 0.90 [95\% Cl: $0.66-1.19]$ events per 100 patient-years) and the rate of fatal bleeding exceeded the rate of fatal PE

Keywords

- venous thromboembolism

- age

- anticoagulant therapy

- hemorrhage

- mortality events ( 0.38 [ $95 \%$ Cl: $0.24-0.58$ ] vs. 0.06 [ $95 \%$ Cl: $0.02-0.16]$ deaths per 100 patient-years). On multivariable analysis, patients who had bled during the first 3 months (hazard ratio [HR]: 4.32; 95\% Cl: 1.58-11.8) or with anemia at baseline (HR: 1.87; 95\% Cl: 1.24-2.81) were at increased risk for bleeding beyond the third month. Patients initially presenting with PE were at increased risk for PE recurrences (HR: 3.60; 95\% Cl: 1.28-10.1).

Conclusion Prolonging anticoagulation beyond the third month was associated with more bleeds than PE recurrences. Prior bleeding, anemia, and initial VTE presentation may help decide when to stop therapy.
\end{abstract}

A full list of the RIETE investigators is given in Appendix A.

received

June 19, 2018

accepted

October 9, 2018
DOI https://doi.org/

$10.1055 / \mathrm{s}-0038-1676359$. ISSN 2512-9465. (c) 2018 Georg Thieme Verlag KG Stuttgart · New York
License terms

(c) (i) 


\section{Introduction}

The decision to prolong or to discontinue anticoagulant therapy beyond the third month in elderly patients with unprovoked venous thromboembolism (VTE) has not been consistently addressed so far. Current guidelines of antithrombotic therapy, based on the results of randomized trials, recommend that patients with unprovoked VTE be treated with anticoagulants for at least 3 months (Grade 1B). ${ }^{1}$ Then, they suggest to prolong anticoagulation in patients at low or moderate risk for bleeding (Grade $2 \mathrm{~B}$ ) and recommend its discontinuation in those with a high risk for bleeding (Grade 1B). Both the frequency of unprovoked VTE and the risk of bleeding progressively increase with age, ${ }^{2-7}$ but elderly patients are often excluded from randomized clinical trials, and the ideal duration of anticoagulation in this patient population remains unknown.

The RIETE (Registro Informatizado de Enfermedad TromboEmbólica) registry is an ongoing, multicenter, international observational registry of consecutive patients with objectively confirmed, acute VTE (ClinicalTrials.gov identifier: NCT02832245). It started in Spain in 2001, and 6 years later the database was translated into English with the aim to expand the registry to other countries, ultimately allowing physicians worldwide to use the database to select the most appropriate therapy for their patients. Data from this registry have been used to evaluate outcomes after acute VTE, such as the frequency of recurrent VTE, bleeding and mortality, and risk factors for these outcomes. ${ }^{8-13}$ The current study analyzed the rate and severity of VTE recurrences and major bleeding events occurring beyond the third month of anticoagulation in patients aged $>75$ years with a first episode of unprovoked VTE. Then, we tried to identify independent predictors for recurrent pulmonary embolism (PE) and for major bleeding.

\section{Patients and Methods}

\section{Inclusion Criteria}

Consecutive patients with symptomatic, acute deep vein thrombosis (DVT) or PE confirmed by objective tests (compression ultrasonography or contrast venography for DVT; helical CT-scan, ventilation-perfusion lung scintigraphy, or angiography for PE) were enrolled in RIETE. The rationale and methodology of RIETE has been recently published. ${ }^{14}$ Patients were excluded if they were currently participating in a therapeutic clinical trial with a blinded therapy. All patients (or their relatives) provided written or oral consent for participation in the registry, in accordance with local ethics committee requirements.

\section{Study Design}

For this study, only patients aged $>75$ years with a first episode of unprovoked PE or proximal DVT were considered. VTE was considered to be unprovoked in the absence of active cancer, recent ( $<2$ months before) immobility, surgery, bone fracture, or long-term travel. DVT was considered proximal if it is located above the popliteal vein. The major outcome was the rate of symptomatic PE recurrences and major bleeding events occurring beyond the first 3 months of anticoagulant therapy. Secondary outcomes were fatal PE recurrences and fatal bleeding. Major bleeding was defined as an overt bleed requiring a transfusion of two or more units of blood, or if it was retroperitoneal, spinal, intracranial, or fatal. Fatal bleeding was defined as any death occurring within 10 days of a major bleeding episode, in the absence of an alternative cause of death. Fatal recurrent PE, in the absence of autopsy, was defined as any death appearing within 10 days of a symptomatic, objectively confirmed PE recurrence, in the absence of any alternative cause of death.

\section{Baseline Variables}

The following parameters were recorded when the qualifying episode of VTE was diagnosed: patient's gender, age and body weight, presence of coexisting conditions, risk factors, concomitant diseases and medications, laboratory data at baseline, and treatment details (drug, dose, and duration). Unfortunately, there is information only on the clinical characteristics of patients or laboratory tests at baseline (not on day 90).

\section{Treatment and Follow-up}

Patients were managed according to the clinical practice of each participating hospital (i.e., there was no standardization of therapy). The drug, dose, and duration of anticoagulant therapy were recorded. The decision on the type and duration of therapy was left to the attending physicians. Patients were followed up in the outpatient clinic (or telephone interviews for patients who could not show up for a clinic visit). During each visit, any signs or symptoms suggesting VTE recurrences or major bleeding were noted. Each episode of clinically suspected recurrent VTE was investigated by repeat compression ultrasonography, lung scan, helical-CT scan, or pulmonary angiography, as appropriate. Most outcomes were classified as reported by the clinical centers.

\section{Statistical Analysis}

Analysis of variance and nonparametric tests were used to compare means and medians of continuous variables. Categorical variables were compared using the chi-square test (two-sided) and Fisher's exact test (two-sided). Incidence rates of recurrent VTE, major bleeding, and death were calculated as cumulative incidence (events/100 patientyears). To measure predictors of outcome, a multivariate analysis was performed using a Cox proportional hazard regression analyses, and the corresponding Kaplan-Meier survival curves were built. Candidate variables were selected from clinical variables based on published literature and on expert opinion. Cut-offs for age and body weight were chosen arbitrarily. Crude and adjusted hazard ratios (HRs) as well as their 95\% confidence intervals (CIs) were estimated. Covariates included in the adjusted model were those for which a statistically significant difference (a threshold $p$-value of 0.1 was set to assess significance of differences) was found, and a backward selection was used for the covariate selection in the multivariable model. SPSS software (version 20, SPSS Inc., 
Chicago, Illinois, United States) was used for the statistical management of the data, and a two-sided $p<0.05$ was considered to be statistically significant.

\section{Results}

As of September 2017, 7,830 patients aged $>75$ years with a first episode of unprovoked VTE were still alive beyond the third month of anticoagulant therapy. Of these, 5,058 patients (65\%) had initially presented with PE (with or without concomitant DVT) and 2,772 with proximal DVT alone. Patients initially presenting with PE were more likely to be women and to have arterial hypertension, chronic heart failure, chronic lung disease, prior artery disease, or renal insufficiency, and were less likely to have anemia than those initially with DVT (- Table 1). In addition, patients initially presenting with PE were more likely to be using nonsteroidal anti-inflammatory drugs or antiplatelets at baseline than those presenting with DVT alone. Most patients in both subgroups (89 and 95\%, respectively) received initial therapy with low-molecular-weight heparin (LMWH). Then, most (81 and 74\%) switched to vitamin $\mathrm{K}$ antagonists (VKAs). Mean duration of therapy beyond the third month was longer in PE patients than in those with DVT (-Table 2). One in every three patients (62\%) was still receiving anticoagulant therapy 180 days after the index event, and one in every four patients (26\%) was still receiving anticoagulant therapy 1 year later.

During the course of anticoagulation beyond the third month (median, 113 days), 44 patients developed PE recurrences, 36 developed DVT recurrences, 101 had major bleeding, and 241 died ( 3 died of recurrent PE and 19 of bleeding). The rate of major bleeding was twofold higher than the rate of PE recurrences (2.05 [95\% CI: 1.68-2.48] vs. 0.90 [95\% CI: $0.66-1.19$ ] events per 100 patient-years) and the rate of fatal bleeding far exceeded the rate of fatal PE events $(0.38$ [95\% CI: $0.24-0.58$ ] vs. 0.06 [95\% CI: 0.02-0.16] deaths per 100 patient-years) (-Fig. 1). Among patients initially presenting with PE, 40 patients developed PE recurrences, 14 had DVT recurrences, 71 had major bleeding, and 198 died (2 died of recurrent PE and 17 of bleeding). Among those initially presenting with DVT, there were 4 PE recurrences, 22 DVT recurrences, 30 major bleeds, and 43 deaths ( 1 patient died of recurrent PE, 2 died of bleeding). Thus, in patients initially presenting with $\mathrm{PE}$, the rate of $\mathrm{PE}$ recurrences was higher than in those with DVT alone $(1.13$ [95\% CI: 0.82-1.52] vs. 0.29 [95\% CI: 0.09-0.70] events per 100 patient-years; $p<$

$0.01)$, but the rate of DVT recurrences was lower (0.39 [95\% CI: $0.22-0.64$ ] vs. 1.63 [95\% CI: 1.05-2.43] events per 100 patient-years; $p<0.001$ ), as shown in - Table 2. There were no differences in the rate of major bleeding, but patients initially presenting with PE had a lower rate of gastrointestinal bleeding than those initially presenting with DVT. When separately analyzing outcomes according to prescribed drugs, the rate of major bleeding exceeded the rate of PE recurrences during the course of therapy in patients receiving VKAs ( 81 vs. 31 events, respectively) and in those on LMWH (17 vs. 11 events, respectively), as also shown in - Table 2. The amount of patients receiving direct oral anticoagulants was too small to make comparisons.

On multivariable analysis, after adjusting for patient's age, sex, body weight, initial VTE presentation (PE vs. DVT alone), underlying diseases, concomitant therapies, renal function, anemia, thrombocytopenia, presence of PE recurrences or major bleeding during the first 3 months, and type of longterm therapy, patients with major bleeding during the first 3 months of therapy (HR: 4.32; 95\% CI: 1.58-11.8) and those presenting with anemia at baseline (HR: $1.87 ; 95 \% \mathrm{CI}: 1.24-$ 2.81) were at increased risk for major bleeding beyond the third month (- Table 3). Moreover, initial presentation as PE at baseline was the only variable that independently predicted risk for PE recurrences (HR: 3.60; 95\% CI: 1.28-10.1).

After excluding 82 patients who developed major bleeding during the first 3 months of therapy, the rate of major bleeding outweighed the rate of PE recurrences in patients initially presenting with DVT (28 vs. 4 events, respectively) and in those presenting with PE and anemia (23 vs. 8 events, respectively), as shown in - Table 4. In PE patients without anemia, however, both rates were closer (46 vs. 31 events).

\section{Discussion}

Our findings, obtained from a large series of patients aged $>75$ years with a first episode of unprovoked VTE, reveal that the rate of major bleeding beyond the third month of therapy was over twofold higher than the rate of PE recurrences (101 vs. 44 events, respectively), and the rate of fatal bleeding also outweighed the rate of fatal PE (19 vs. 3 deaths). The higher rate and severity of major bleeding than recurrent PE was consistently found in patients receiving long-term therapy with VKAs or LMWH. Therefore, the clinical relevance of bleeding beyond the third month should not be underestimated, even in patients that did not bleed during the first 3 months. On the contrary, accurate identification of at-risk patients is urgently needed.

In our cohort, patients presenting with major bleeding during the first 3 months had an over fourfold higher risk to rebleed beyond the third month. We firmly believe that most of these patients would have benefited from earlier discontinuation of anticoagulant therapy. This is the reason why we re-evaluated the outcomes after excluding patients that bled during the first 3 months. Then, we found that patients initially presenting with DVT (2,746 of 7,748 patients, $35 \%)$ had a particularly low rate of PE recurrences, and those with anemia at baseline (28\%) had a much higher rate of major bleeding than those without anemia. The higher risk for bleeding in patients with anemia has already been reported previously. ${ }^{1,2,4,5,15-18}$ The lower rate of PE recurrences in patients initially presenting with DVT than in those with PE has also been reported in several studies. ${ }^{19-21}$ Hence, adequately designed, randomized trials comparing only 3 months versus prolonged anticoagulation beyond the third month in patients with DVT or anemia would likely provide information about the ideal duration of therapy in this patient population. In the meantime, we suggest that most 
Table 1 Clinical characteristics at baseline and treatment, according to initial VTE presentation

\begin{tabular}{|c|c|c|c|}
\hline & $\begin{array}{l}\text { Pulmonary } \\
\text { embolism }\end{array}$ & $\begin{array}{l}\text { Proximal deep } \\
\text { vein thrombosis }\end{array}$ & Odds ratio $(95 \% \mathrm{Cl})$ \\
\hline Patients, $N$ & 5,058 & 2,772 & \\
\hline \multicolumn{4}{|l|}{ Clinical characteristics } \\
\hline Gender (male) & $1,795(35 \%)$ & $1,198(43 \%)$ & $0.72(0.66-0.79)$ \\
\hline Age $(y \pm S D)$ & $82 \pm 4.7$ & $82 \pm 4.7$ & - \\
\hline Weight $(\mathrm{kg} \pm \mathrm{SD})$ & $72 \pm 13$ & $72 \pm 13$ & - \\
\hline \multicolumn{4}{|l|}{ Concomitant diseases } \\
\hline Diabetes mellitus & $594(12 \%)$ & $298(11 \%)$ & $1.10(0.95-1.28)$ \\
\hline Arterial hypertension & $2,377(47 \%)$ & $1,058(38 \%)$ & $1.44(1.31-1.58)$ \\
\hline Chronic heart failure & $718(14 \%)$ & $180(6.5 \%)$ & $2.38(2.01-2.83)$ \\
\hline Chronic lung disease & $818(16 \%)$ & $291(10 \%)$ & $1.64(1.43-1.90)$ \\
\hline Prior myocardial infarction & $378(7.5 \%)$ & $132(4.8 \%)$ & $1.62(1.32-1.98)$ \\
\hline Prior ischemic stroke & $350(6.9 \%)$ & $111(4.0 \%)$ & $1.78(1.43-2.22)$ \\
\hline Recent major bleeding & $40(0.79 \%)$ & $13(0.47 \%)$ & $1.69(0.90-3.17)$ \\
\hline Major bleeding within $3 \mathrm{mo}$ & $56(1.1 \%)$ & $26(0.94 \%)$ & $1.18(0.74-1.89)$ \\
\hline \multicolumn{4}{|l|}{ Events from day 0 to day 90} \\
\hline Major bleeding & $56(1.1 \%)$ & $26(0.94 \%)$ & $1.18(0.74-1.89)$ \\
\hline PE recurrences & $11(0.22 \%)$ & $7(0.25 \%)$ & $0.86(0.33-2.22)$ \\
\hline \multicolumn{4}{|l|}{ Concomitant therapies } \\
\hline Corticosteroids & $350(6.9 \%)$ & $167(6.0 \%)$ & $1.16(0.96-1.40)$ \\
\hline NSAIDs & $287(5.7 \%)$ & $124(4.5 \%)$ & $1.28(1.04-1.59)$ \\
\hline Antiplatelets & $1,246(25 \%)$ & $472(17 \%)$ & $1.59(1.42-1.79)$ \\
\hline \multicolumn{4}{|l|}{ Laboratory tests at baseline } \\
\hline $\mathrm{CrCl}$ levels $<30 \mathrm{~mL} / \mathrm{min}$ & $631(12 \%)$ & $312(11 \%)$ & $1.12(0.97-1.30)$ \\
\hline $\mathrm{CrCl}$ levels $<60 \mathrm{~mL} / \mathrm{min}$ & $3,704(73 \%)$ & $1,916(69 \%)$ & $1.22(1.10-1.35)$ \\
\hline Anemia & $1,312(26 \%)$ & $868(31 \%)$ & $0.77(0.69-0.85)$ \\
\hline Abnormal platelet count & $170(3.4 \%)$ & $86(3.1 \%)$ & $1.09(0.83-1.41)$ \\
\hline \multicolumn{4}{|l|}{ Initial therapy } \\
\hline Low-molecular-weight heparin & $4,502(89 \%)$ & $2,642(95 \%)$ & $0.40(0.33-0.49)$ \\
\hline Unfractionated heparin & $372(7.4 \%)$ & $50(1.8 \%)$ & $4.32(3.20-5.83)$ \\
\hline Direct oral anticoagulants & $33(0.65 \%)$ & 39 (1.4\%) & $0.46(0.29-0.73)$ \\
\hline Fondaparinux & $58(1.1 \%)$ & $26(0.94 \%)$ & $1.23(0.77-1.95)$ \\
\hline Vena cava filter & $49(0.97 \%)$ & $10(0.36 \%)$ & $2.70(1.37-5.34)$ \\
\hline \multicolumn{4}{|l|}{ Long-term therapy } \\
\hline Vitamin K antagonists & $4,077(81 \%)$ & $2,053(74 \%)$ & $1.46(1.30-1.62)$ \\
\hline Low-molecular-weight heparin & $705(14 \%)$ & $563(20 \%)$ & $0.64(0.56-0.72)$ \\
\hline Direct oral anticoagulants & $246(4.9 \%)$ & $130(4.7 \%)$ & $1.04(0.84-1.29)$ \\
\hline \multicolumn{4}{|l|}{ Duration of therapy } \\
\hline Mean days \pm SD & $261 \pm 395$ & $181 \pm 285$ & - \\
\hline Median days (IQR) & $125(57-288)$ & $99(33-210)$ & - \\
\hline Patients treated $>6$ mo & $3,308(65 \%)$ & $1,574(57 \%)$ & $1.44(1.31-1.58)$ \\
\hline Patients treated $>12 \mathrm{mo}$ & $1,500(30 \%)$ & $533(19 \%)$ & $1.77(1.58-1.98)$ \\
\hline
\end{tabular}

Abbreviations: $\mathrm{Cl}$, confidence intervals; $\mathrm{CrCl}$, creatinine clearance; IQR, interquartile range; NSAIDs, nonsteroidal anti-inflammatory drugs; $\mathrm{PE}$, pulmonary embolism; SD, standard deviation; VTE, venous thromboembolism. 


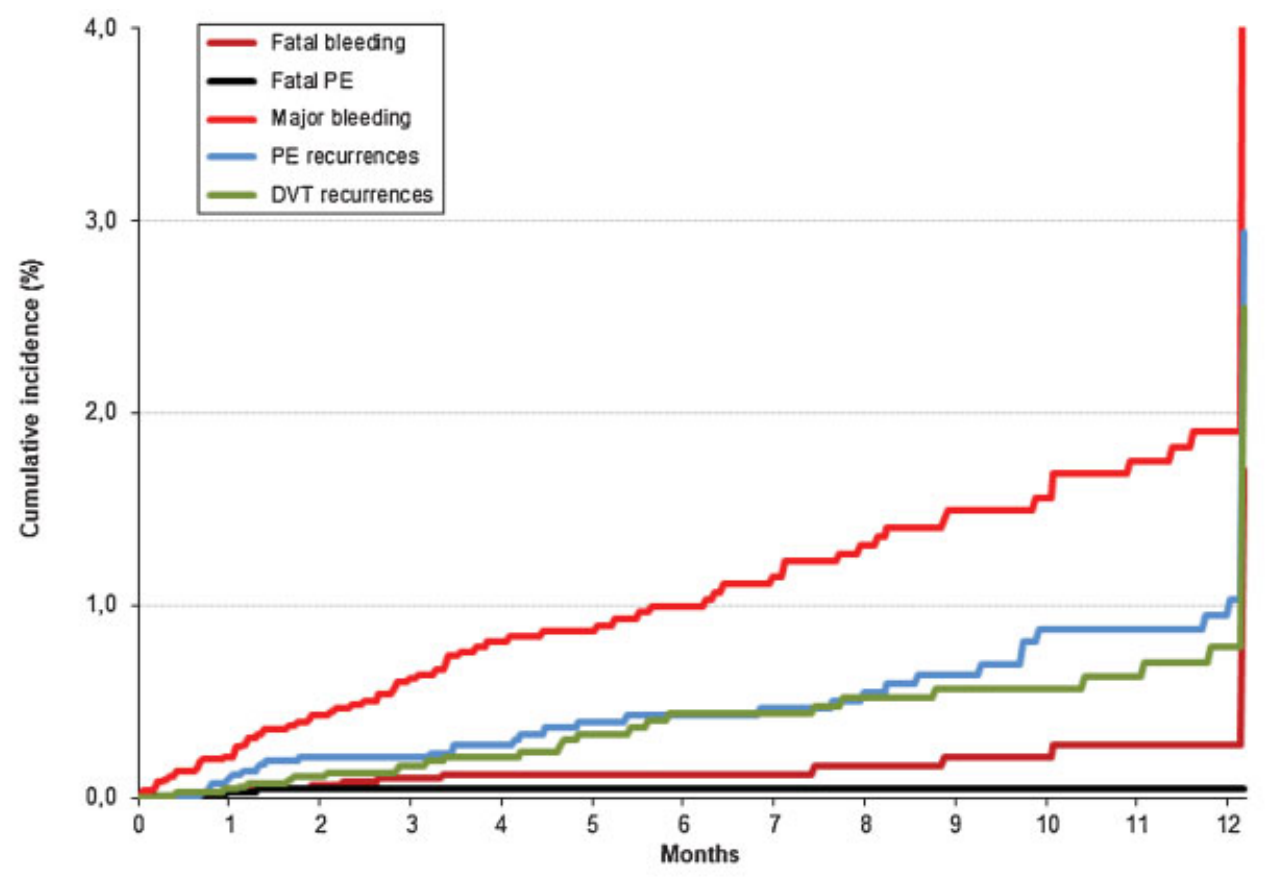

\begin{tabular}{|l|c|c|c|c|c|c|}
\hline Days & $\mathbf{1 5}$ & $\mathbf{3 0}$ & $\mathbf{9 0}$ & $\mathbf{1 8 0}$ & $\mathbf{2 4 0}$ & $\mathbf{3 6 0}$ \\
\hline Patients at risk & $\mathbf{7 , 3 1 1}$ & $\mathbf{6 , 5 4 5}$ & $\mathbf{5 , 6 1 3}$ & $\mathbf{3 , 8 6 1}$ & $\mathbf{2 , 5 6 0}$ & $\mathbf{1 , 7 9 0}$ \\
\hline PE recurrences & $1(0.01 \%)$ & $7(0.11 \%)$ & $13(0.21 \%)$ & $21(0.43 \%)$ & $24(0.55 \%)$ & $32(1.03 \%)$ \\
\hline DVT recurrences & $2(0.03 \%)$ & $3(0.04 \%)$ & $10(0.17 \%)$ & $19(0.43 \%)$ & $21(0.52 \%)$ & $25(0.78 \%)$ \\
\hline Major bleeding & $10(0.14 \%)$ & $15(0.21 \%)$ & $38(0.62 \%)$ & $52(1.0 \%)$ & $60(1.31 \%)$ & $70(1.9 \%)$ \\
\hline Fatal PE & $1(0.01 \%)$ & $2(0.03 \%)$ & $3(0.05 \%)$ & $3(0.05 \%)$ & $3(0.05 \%)$ & $3(0.05 \%)$ \\
\hline Fatal bleeding & $2(0.03 \%)$ & $2(0.03 \%)$ & $6(0.10 \%)$ & $7(0.12 \%)$ & $8(0.16 \%)$ & $10(0.28 \%)$ \\
\hline
\end{tabular}

Fig. 1 Cumulative rates of recurrent PE, recurrent DVT, major bleeding, fatal PE, and fatal bleeding during anticoagulant therapy (beyond the third month). Day 0 in the figure means day 91 of anticoagulant therapy. DVT, deep vein thrombosis; PE, pulmonary embolism.

patients aged $>75$ years presenting with unprovoked DVT or with anemia at baseline would likely benefit from early (3 months) discontinuation of therapy.

The present study has several limitations. First, RIETE is an observational registry, not a randomized trial. Our data are hypothesis-generating and might be a useful basis for future controlled clinical trials, so we should be extremely cautious in suggesting changes in treatment strategies just because of registry data. Second, treatment varied with local practice, and is likely to have been influenced by a physician's assessment of patient's risk of bleeding. Third, it is mandatory in RIETE that patients must experience an objectively confirmed recurrent $P E$ followed by death within the previous 10 days to be considered as fatal PE. Thus, it is possible that some deaths of unknown cause were truly PE-related deaths. However, some patients may have also died of myocardial infarction, ischemic stroke, or even intracranial bleeding.
Finally, the numbers of patients in the respective subgroups tend to be small, which may render the statistical analyses meaningless. Strengths of the current analysis include that the RIETE registry provides data on the treatment of VTE in a real-world situation with an unselected patient population, in contrast to the rigorously controlled conditions of randomized clinical trials. This is important because our patient population reflects routine, unmonitored medical practice involving a broad spectrum of patients with VTE. Moreover, all VTE recurrences were confirmed by objective tests.

In summary, prolonging anticoagulant therapy beyond the third month in patients aged $>75$ years with unprovoked VTE was associated with a higher rate of major bleeding than PE recurrences, and a higher rate of fatal bleeding than fatal PE. Prior bleeding during the first 3 months, anemia at baseline, and initial VTE presentation may help decide when to stop therapy. 
Anticoagulation in Elderly VTE Patients Iñurrieta et al. e433

Table 2 Clinical outcomes beyond the third month of anticoagulant therapy, according to initial VTE presentation and treatment

\begin{tabular}{|c|c|c|c|c|c|c|}
\hline & \multicolumn{2}{|c|}{ All patients } & \multicolumn{2}{|c|}{ Pulmonary embolism } & \multicolumn{2}{|c|}{ Proximal DVT } \\
\hline & $N$ & $\begin{array}{l}\text { Events per } 100 \\
\text { patient-years }\end{array}$ & $N$ & $\begin{array}{l}\text { Events per } 100 \\
\text { patient-years }\end{array}$ & $N$ & $\begin{array}{l}\text { Events per } 100 \\
\text { patient-years }\end{array}$ \\
\hline Patients, $N$ & \multicolumn{2}{|c|}{7,830} & \multicolumn{2}{|c|}{5,058} & \multicolumn{2}{|c|}{2,772} \\
\hline \multicolumn{7}{|l|}{ Duration of therapy } \\
\hline Mean days \pm SD & \multicolumn{2}{|c|}{$232 \pm 362$} & \multicolumn{2}{|c|}{$261 \pm 395$} & \multicolumn{2}{|c|}{$181 \pm 285^{* * *}$} \\
\hline Median days (IQR) & \multicolumn{2}{|c|}{$113(46-275)$} & \multicolumn{2}{|c|}{$125(57-288)$} & \multicolumn{2}{|c|}{$99(33-210)^{* * * *}$} \\
\hline Recurrent PE & 44 & $0.90(0.66-1.19)$ & 40 & $1.13(0.82-1.52)$ & 4 & $0.29(0.09-0.70)^{* *}$ \\
\hline Recurrent DVT & 36 & $0.73(0.52-1.00)$ & 14 & $0.39(0.22-0.64)$ & 22 & $1.63(1.05-2.43)^{* * *}$ \\
\hline Major bleeding & 101 & $2.05(1.68-2.48)$ & 71 & $1.98(1.56-2.49)$ & 30 & $2.21(1.52-3.12)$ \\
\hline \multicolumn{7}{|l|}{ Sites of major bleeding } \\
\hline Gastrointestinal & 40 & $0.81(0.58-1.09)$ & 23 & $0.64(0.41-0.94)$ & 17 & $1.25(0.75-1.96)^{*}$ \\
\hline Cerebral & 37 & $0.75(0.53-1.02)$ & 31 & $0.86(0.60-1.21)$ & 6 & $0.44(0.18-0.91)$ \\
\hline Death & 241 & $4.84(4.26-5.48)$ & 198 & $5.49(4.76-6.29)$ & 43 & $3.13(2.30-4.18)^{* * *}$ \\
\hline \multicolumn{7}{|l|}{ Causes of death } \\
\hline Pulmonary embolism & 3 & $0.06(0.02-0.16)$ & 2 & $0.06(0.01-0.18)$ & 1 & $0.07(0.00-0.36)$ \\
\hline Bleeding & 19 & $0.38(0.24-0.58)$ & 17 & $0.47(0.28-0.74)$ & 2 & $0.15(0.02-0.48)$ \\
\hline Patients on VKA, $N$ & \multicolumn{2}{|c|}{6,130} & \multicolumn{2}{|c|}{4,077} & \multicolumn{2}{|c|}{2,053} \\
\hline Recurrent PE & 31 & $0.75(0.52-1.06)$ & 27 & $0.91(0.61-1.30)$ & 4 & $0.35(0.11-0.85)$ \\
\hline Recurrent DVT & 31 & $0.75(0.52-1.05)$ & 12 & $0.40(0.22-0.68)$ & 19 & $1.70(1.05-2.60)^{* * * *}$ \\
\hline Major bleeding & 81 & $1.97(1.57-2.43)$ & 57 & $1.91(1.46-2.45)$ & 24 & $2.14(1.40-3.13)$ \\
\hline Death & 183 & $4.40(3.80-5.07)$ & 157 & $5.20(4.43-6.06)$ & 26 & $2.28(1.52-3.30)^{* * *}$ \\
\hline Patients on LMWH, $N$ & \multicolumn{2}{|c|}{1,268} & \multicolumn{2}{|l|}{705} & \multicolumn{2}{|c|}{563} \\
\hline Recurrent PE & 11 & $1.83(0.96-3.17)$ & 11 & $2.59(1.36-4.51)$ & 0 & - \\
\hline Recurrent DVT & 4 & $0.65(0.21-1.57)$ & 2 & $0.45(0.08-1.50)$ & 2 & $1.15(0.19-3.79)$ \\
\hline Major bleeding & 17 & $2.74(1.65-4.30)$ & 11 & $2.48(1.31-4.32)$ & 6 & $3.39(1.37-7.04)$ \\
\hline Death & 51 & $8.20(6.17-10.7)$ & 38 & $8.57(6.15-11.6)$ & 13 & $7.29(4.06-12.2)$ \\
\hline Patients on DOACs, $N$ & \multicolumn{2}{|l|}{376} & \multicolumn{2}{|l|}{246} & \multicolumn{2}{|c|}{130} \\
\hline Recurrent PE & 2 & $1.13(0.19-3.75)$ & 2 & $1.56(0.26-5.16)$ & 0 & - \\
\hline Recurrent DVT & 1 & $0.57(0.03-2.79)$ & 0 & - & 1 & $2.10(0.11-10.4)$ \\
\hline Major bleeding & 2 & $1.13(0.19-3.72)$ & 2 & $1.55(0.26-5.12)$ & 0 & - \\
\hline Death & 4 & $2.25(0.72-5.44)$ & 2 & $1.55(0.26-5.12)$ & 2 & $4.14(0.69-13.7)$ \\
\hline
\end{tabular}

Abbreviations: $\mathrm{Cl}$, confidence intervals; DOACs, direct oral anticoagulants; DVT, deep vein thrombosis; IQR, interquartile range; LMWH, lowmolecular-weight heparin; PE, pulmonary embolism; SD, standard deviation; VKA, vitamin K antagonists.

Note: Comparisons between patients with PE or DVT: ${ }^{*} p<0.05 ;{ }^{* *} p<0.01 ;{ }^{* * *} p<0.001$. 
e434 Anticoagulation in Elderly VTE Patients Iñurrieta et al.

Table 3 Uni- and multivariable analysis for major bleeding and for PE recurrences

\begin{tabular}{|c|c|c|c|c|}
\hline & \multicolumn{2}{|l|}{ Major bleeding } & \multicolumn{2}{|l|}{ PE recurrences } \\
\hline & $\begin{array}{l}\text { Nonadjusted } \\
\text { HR (95\% CI) }\end{array}$ & $\begin{array}{l}\text { Adjusted } \\
\text { HR }(95 \% \mathrm{Cl})\end{array}$ & $\begin{array}{l}\text { Nonadjusted } \\
\text { HR }(95 \% \mathrm{CI})\end{array}$ & $\begin{array}{l}\text { Adjusted } \\
\text { HR }(95 \% \mathrm{Cl})\end{array}$ \\
\hline Patients, $N$ & \multicolumn{2}{|l|}{101} & \multicolumn{2}{|l|}{44} \\
\hline \multicolumn{5}{|l|}{ Clinical characteristics } \\
\hline Gender (male) & $1.33(0.89-1.96)$ & - & $0.65(0.34-1.25)$ & - \\
\hline Age $>82$ y & $1.50(1.01-2.22)$ & $1.30(0.86-1.96)$ & $1.69(0.93-3.05)$ & $1.38(0.74-2.58)$ \\
\hline Weight > $70 \mathrm{~kg}$ & $0.73(0.49-1.08)$ & - & $0.52(0.28-0.96)$ & $0.58(0.30-1.13)$ \\
\hline \multicolumn{5}{|l|}{ Initial VTE presentation } \\
\hline Pulmonary embolism & $0.92(0.60-1.41)$ & $0.91(0.59-1.41)$ & $3.99(1.42-11.16)$ & $3.60(1.28-10.1)$ \\
\hline \multicolumn{5}{|l|}{ Concomitant diseases } \\
\hline Diabetes & $1.09(0.62-1.93)$ & - & $1.03(0.44-2.45)$ & - \\
\hline Arterial hypertension & $1.45(0.98-2.16)$ & $1.38(0.92-2.08)$ & $1.11(0.62-2.01)$ & - \\
\hline Chronic heart failure & $0.78(0.41-1.50)$ & - & $2.37(1.20-4.69)$ & $1.86(0.93-3.73)$ \\
\hline Chronic lung disease & $1.11(0.65-1.89)$ & - & $0.74(0.29-1.87)$ & - \\
\hline Prior myocardial infarction & $1.10(0.53-2.26)$ & - & $1.98(0.84-4.69)$ & - \\
\hline Prior ischemic stroke & $1.71(0.91-3.19)$ & $1.49(0.79-2.82)$ & $2.13(0.90-5.05)$ & $1.67(0.70-3.99)$ \\
\hline Recent major bleeding & $1.92(0.27-13.8)$ & - & $4.66(0.64-33.9)$ & - \\
\hline \multicolumn{5}{|l|}{ Events from day 0 to day 90} \\
\hline Major bleeding & $4.40(1.62-12.0)$ & $4.32(1.58-11.8)$ & $2.38(0.33-17.3)$ & - \\
\hline PE recurrences & - & - & - & - \\
\hline \multicolumn{5}{|l|}{ Concomitant therapies } \\
\hline Corticosteroids & $1.58(0.82-3.04)$ & - & $1.02(0.32-3.30)$ & - \\
\hline NSAIDs & $0.84(0.34-2.08)$ & - & $2.07(0.82-5.25)$ & - \\
\hline Antiplatelets & $0.86(0.53-1.40)$ & - & $1.66(0.89-3.09)$ & - \\
\hline \multicolumn{5}{|l|}{ Laboratory tests at baseline } \\
\hline $\mathrm{CrCl}$ levels $>60 \mathrm{~mL} / \mathrm{min}$ & (Ref.) & (Ref.) & (Ref.) & (Ref.) \\
\hline $\mathrm{CrCl}$ levels $30-60 \mathrm{~mL} / \mathrm{min}$ & $1.20(0.74-1.92)$ & $1.08(0.67-1.76)$ & $1.22(0.59-2.54)$ & $0.85(0.39-1.87)$ \\
\hline $\mathrm{CrCl}$ levels $<30 \mathrm{~mL} / \mathrm{min}$ & $1.87(1.01-3.49)$ & $1.37(0.72-2.63)$ & $2.40(0.98-5.91)$ & $1.23(0.45-3.37)$ \\
\hline Anemia & $2.01(1.35-3.01)$ & $1.87(1.24-2.81)$ & $0.91(0.45-1.85)$ & - \\
\hline Abnormal platelet count & $0.05(0.00-6.15)$ & - & $0.67(0.09-4.84)$ & - \\
\hline \multicolumn{5}{|l|}{ Long-term therapy } \\
\hline Vitamin $\mathrm{K}$ antagonists & $0.82(0.50-1.35)$ & - & $0.48(0.25-0.92)$ & $0.81(0.19-3.43)$ \\
\hline LMWH & $1.38(0.82-2.33)$ & - & $2.33(1.18-4.61)$ & $1.77(0.39-8.10)$ \\
\hline Direct oral anticoagulants & $0.53(0.13-2.15)$ & - & $1.23(0.30-5.08)$ & - \\
\hline
\end{tabular}

Abbreviations: $\mathrm{Cl}$, confidence intervals; $\mathrm{CrCl}$, creatinine clearance; HR, hazard ratio; LMWH, low-molecular-weight heparin; NSAIDs, nonsteroidal anti-inflammatory drugs; PE, pulmonary embolism; Ref, reference; VTE, venous thromboembolism. 
Table 4 Clinical outcomes during anticoagulation in the 7,748 patients that did not bled during the first 3 months, according to initial VTE presentation and the presence or absence of anemia at baseline

\begin{tabular}{|c|c|c|c|c|c|}
\hline & \multicolumn{2}{|c|}{ Anemia } & \multicolumn{2}{|c|}{ No anemia } & \multirow[t]{2}{*}{ Hazard ratio $(95 \% \mathrm{Cl})$} \\
\hline & $N$ & Events per 100 patient-years & $N$ & Events per 100 patient-years & \\
\hline PE patients, $N$ & \multicolumn{2}{|c|}{1,291} & \multicolumn{2}{|c|}{3,711} & \\
\hline Recurrent DVT & 2 & $0.26(0.04-0.87)$ & 12 & $0.43(0.23-0.73)$ & $0.61(0.09-2.43)$ \\
\hline Recurrent PE & 8 & $1.07(0.50-2.03)$ & 31 & $1.12(0.78-1.58)$ & $0.95(0.41-2.00)$ \\
\hline Major bleeding & 23 & $3.04(1.97-4.49)$ & 46 & $1.65(1.22-2.18)$ & $1.84(1.10-3.02)$ \\
\hline \multicolumn{6}{|c|}{ Sites of major bleeding } \\
\hline Intracranial & 7 & $0.92(0.40-1.82)$ & 22 & $0.79(0.51-1.17)$ & $1.17(0.46-2.67)$ \\
\hline Gastrointestinal & 10 & $1.32(0.67-2.35)$ & 13 & $0.46(0.26-0.77)$ & $2.85(1.21-6.55)$ \\
\hline Death & 68 & $8.95(7.00-11.3)$ & 127 & $4.52(3.78-5.36)$ & $1.98(1.47-2.65)$ \\
\hline DVT patients, $N$ & \multicolumn{2}{|c|}{856} & \multicolumn{2}{|c|}{1,890} & \\
\hline Recurrent DVT & 7 & $1.74(0.76-3.44)$ & 15 & $1.60(0.93-2.58)$ & $1.09(0.41-2.63)$ \\
\hline Recurrent PE & 2 & $0.49(0.08-1.60)$ & 2 & $0.21(0.04-0.70)$ & $2.30(0.24-22.1)$ \\
\hline Major bleeding & 14 & 3.49 (1.99-5.72) & 14 & $1.48(0.84-2.42)$ & $2.36(1.11-5.03)$ \\
\hline \multicolumn{6}{|c|}{ Sites of major bleeding } \\
\hline Gastrointestinal & 10 & $2.48(1.26-4.42)$ & 6 & $0.63(0.26-1.32)$ & $3.92(1.42-11.6)$ \\
\hline Intracranial & 1 & $0.24(0.01-1.20)$ & 5 & $0.53(0.19-1.17)$ & $0.46(0.02-3.33)$ \\
\hline Death & 14 & $3.39(1.93-5.56)$ & 29 & $3.05(2.08-4.33)$ & $1.11(0.57-2.09)$ \\
\hline
\end{tabular}

Abbreviations: $\mathrm{Cl}$, confidence intervals; DVT, deep vein thrombosis; PE, pulmonary embolism.

Conflict of Interest

None declared.

\section{Acknowledgments}

We express our gratitude to Sanofi Spain for supporting this registry with an unrestricted educational grant. We also express our gratitude to Bayer Pharma AG for supporting this registry. Bayer Pharma AG's support was limited to the part of RIETE outside Spain, which accounts for $22.19 \%$ of the total patients included in the RIETE registry. We also thank the RIETE registry Coordinating Center, S\&H Medical Science Service, for their quality control data and logistic and administrative support, and Prof. Salvador Ortiz, Universidad Autónoma de Madrid and Statistical Advisor S\&H Medical Science Service, for the statistical analysis of the data presented in this paper.

\section{References}

1 Kearon C, Akl EA, Ornelas J, et al. Antithrombotic therapy for VTE disease: CHEST Guideline and Expert Panel Report. Chest 2016; 149(02):315-352

2 Silverstein MD, Heit JA, Mohr DN, Petterson TM, O'Fallon WM, Melton LJ III. Trends in the incidence of deep vein thrombosis and pulmonary embolism: a 25-year population-based study. Arch Intern Med 1998;158(06):585-593

3 Cushman M, Tsai AW, White RH, et al. Deep vein thrombosis and pulmonary embolism in two cohorts: the longitudinal investigation of thromboembolism etiology. Am J Med 2004;117(01):19-25

4 Ruíz-Giménez N, Suárez C, González R, et al; RIETE Investigators. Predictive variables for major bleeding events in patients present- ing with documented acute venous thromboembolism. Findings from the RIETE Registry. Thromb Haemost 2008;100(01):26-31

5 Nieto JA, Solano R, Ruiz-Ribó MD, et al; Riete Investigators. Fatal bleeding in patients receiving anticoagulant therapy for venous thromboembolism: findings from the RIETE registry. J Thromb Haemost 2010;8(06):1216-1222

6 Kearon C, Ginsberg JS, Kovacs MJ, et al; Extended Low-Intensity Anticoagulation for Thrombo-Embolism Investigators. Comparison of low-intensity warfarin therapy with conventional-intensity warfarin therapy for long-term prevention of recurrent venous thromboembolism. N Engl J Med 2003;349(07):631-639

7 Kuijer PM, Hutten BA, Prins MH, Büller HR. Prediction of the risk of bleeding during anticoagulant treatment for venous thromboembolism. Arch Intern Med 1999;159(05):457-460

8 Blanco-Molina Á, Trujillo-Santos J, Pesavento R, et al; RIETE Investigators. Outcome after discontinuing anticoagulant therapy in women with venous thromboembolism during hormonal use. Thromb Res 2017;151(Suppl 1):S6-S10

9 Trujillo-Santos J, Martos FM, Font C, et al. Analysis of clinical factors affecting the rates of fatal pulmonary embolism and bleeding in cancer patients with venous thromboembolism. Heliyon 2017;3 (01):e00229

10 Lacruz B, Tiberio G, Núñez MJ, et al; RIETE Investigators. Venous thromboembolism in centenarians: Findings from the RIETE registry. Eur J Intern Med 2016;36:62-66

11 Pedrajas JM, Garmendia C, Portillo J, et al. Idiopathic versus secondary venous thromboembolism. Findings of the RIETE registry. Rev Clin Esp 2014;214(07):357-364

12 Lecumberri R, Alfonso A, Jiménez D, et al; RIETE investigators. Dynamics of case-fatalilty rates of recurrent thromboembolism and major bleeding in patients treated for venous thromboembolism. Thromb Haemost 2013;110(04):834-843

13 Vasco B, Villalba JC, Lopez-Jimenez L, et al; RIETE Investigators. Venous thromboembolism in nonagenarians. Findings from the RIETE Registry. Thromb Haemost 2009;101(06):1112-1118 
14 Bikdeli B, Jimenez D, Hawkins $\mathrm{M}$, et al; RIETE Investigators. Rationale, design and methodology of the computerized registry of patients with venous thromboembolism (RIETE). Thromb Haemost 2018;118(01):214-224

15 Kuperman A, López-Reyes R, Bosco LJ, et al; RIETE Investigators. Anemia and bleeding in patients receiving anticoagulant therapy for venous thromboembolism. J Thromb Thrombolysis 2018;45 (03):360-368

16 Klok FA, Hösel V, Clemens A, et al. Prediction of bleeding events in patients with venous thromboembolism on stable anticoagulation treatment. Eur Respir J 2016;48(05):1369-1376

17 Di Nisio M, Ageno W, Rutjes AWS, Pap AF, Büller HR. Risk of major bleeding in patients with venous thromboembolism treated with rivaroxaban or with heparin and vitamin $\mathrm{K}$ antagonists. Thromb Haemost 2016;115(02):424-432

\section{Appendix A}

Coordinator of the RIETE Registry: Monreal M (Spain). RIETE Steering Committee Members: Decousus $\mathrm{H}$ (France), Prandoni P (Italy), Brenner B (Israel).

RIETE National Coordinators: Barba R (Spain), Di Micco P (Italy), Bertoletti L (France), Schellong S (Germany), Tzoran I (Israel), Reis A (Portugal), Bosevski M (R. Macedonia), Bounameaux H (Switzerland), Malý R (Czech Republic), Wells P (Canada), Papadakis M (Greece).

RIETE Registry Coordinating Center: S \& H Medical Science Service.

Members of the RIETE Group: SPAIN: Adarraga MD, Andújar V, Arcelus JI, Ballaz A, Barba R, Barrón M, BarrónAndrés B, Bascuñana J, Blanco-Molina A, Bueso T, Cañas I, Casado I, del Molino F, del Toro J, Díaz JA, Falgá C, FernándezCapitán C, Font L, Gallego P, García-Bragado F, Gómez V, González J, Grau E, Guijarro R, Guil M, Guirado L, Gutiérrez J, Hernández-Blasco L, Hernández-Huerta S, Jara-Palomares L, Jaras MJ, Jiménez D, Jiménez R, Lacruz B, Lecumberri R, Lobo JL, López-Jiménez L, López-Reyes R, López-Sáez JB, Lorente MA,
18 Di Nisio M, Raskob G, Büller HR, et al. Prediction of major and clinically relevant bleeding in patients with VTE treated with edoxaban or vitamin K antagonists. Thromb Haemost 2017;117(04):784-793

19 Prandoni P, Noventa F, Ghirarduzzi A, et al. The risk of recurrent venous thromboembolism after discontinuing anticoagulation in patients with acute proximal deep vein thrombosis or pulmonary embolism. A prospective cohort study in 1,626 patients. Haematologica 2007;92(02):199-205

20 Kyrle PA, Kammer M, Eischer L, et al. The long-term recurrence risk of patients with unprovoked venous thromboembolism: an observational cohort study. J Thromb Haemost 2016;14(12):2402-2409

21 Baglin T, Douketis J, Tosetto A, et al. Does the clinical presentation and extent of venous thrombosis predict likelihood and type of recurrence? A patient-level meta-analysis. J Thromb Haemost 2010;8(11):2436-2442

Lorenzo A, Madridano O, Maestre A, Marchena PJ, MartínAntorán JM, Martín-Martos F, Monreal M, Morales MV, Nauffal D, Nieto JA, Núñez MJ, Odriozola M, Otalora S, Otero R, Pagán B, Pedrajas JM, Peris ML, Pons I, Porras JA, Riera-Mestre A, Rivas A, Rodríguez-Dávila MA, Rosa V, Rosa-Silvia A, Ruiz-Giménez N, Ruiz-Martínez C, Sabio P, Sampériz A, Sánchez R, Sanz O, Soler S, Suriñach JM, Tiberio G, Tirado R, Tolosa C, Trujillo-Santos J, Uresandi F, Valero B, Valle R, Vela J, Vilar C, Villalobos A, Villalta J, ARGENTINA: Malfante P, BELGIUM: Vanassche T, Verhamme P, CANADA: Wells P, CZECH REPUBLIC: Hirmerova J, Malý R, Tomko T, FRANCE: Bertoletti L, Bura-Riviere A, Farge-Bancel D, Hij A, Mahe I, Merah A, Moustafa F, GERMANY: Schellong S, GREECE: Babalis D, Papadakis M, Tzinieris I, ISRAEL: Braester A, Brenner B, Tzoran I, ITALY: Apollonio A, Barillari G, Bucherini E, Camerota A, Ciammaichella M, Di Micco P, Ferrazzi P, Maida R, Mastroiacovo D, Pace F, Pasca S, Pesavento R, Pinelli M, Piovella C, Prandoni P, Rota L, Tiraferri E, Tonello D, Tufano A, Visonà A, Zalunardo B, LATVIA: Skride A, PORTUGAL: Mafalda A, Ribeiro JL, Sousa MS, REPUBLIC OF MACEDONIA: Bosevski M, SWITZERLAND: Alatri A, Bounameaux H, Calanca L, Mazzolai L, VENEZUELA: Serrano JC. 